\title{
La revolución cubana y la economía, 1959-2012. Los ciclos de política y el ciclo azucarero*/
} The Cuban revolution and the economy, 1959-2012. The politic cycles and the sugar cycle

\author{
Antonio Santamaría García \\ Instituto de Historia, CSIC
}

A Adolfo Suárez

Este artículo sostiene que el principal problema económico de Cuba tras la extinción de la URSS ha sido el fin de dos siglos de especialización en producir azúcar, pues la aparición de un nuevo socio, Venezuela, no proporcionó un mercado alternativo. Además muestra que las políticas aplicadas no han afrontado radicalmente la situación, y analiza las reformas recientes, que diseñan un programa para aliviarlos, pero sin modificar el sistema socio-económico y político.

Palabras Clave: Cuba, Economía, Revolución Cubana, Economía Socialista Cubana, Reformas Revolucionarias

This article argues that the main problem of the Cuban economy before the extinction of the URSS has been the end of two centuries of specialization in the sugar production, since the emergence of a new partner, Venezuela, did not provide an alternative market. The paper shows that policies have not addressed radically the situation, and analyzes the recent reforms as a program designed to alleviate them, but without changes in the socio-economic and political system.

KeYwords: Cuba, Economy, Cuban Revolution, Cuban Socialist Economy, Revolutionary Reforms

* Agradezco los comentarios de los referees y de Sigfrido Vázquez Cienfuegos. 
Al comenzar la década de 1990 la disolución de la URSS finiquitó la relación que tenía con Cuba desde el inicio de su revolución. De ella recibía ayudas y petróleo barato y a ella y al CAME enviaba azúcar a precios subsidiados. El establecimiento de esa relación provocó el abandono del plan de diversificación diseñado originalmente por el gobierno castrista y compensó el embargo de EEUU, pero también reforzó la especialización económica, progresiva desde finales del siglo XVIII.

En 1990 acabaron abruptamente para Cuba dos siglos de especialización económica sin alternativas. Durante su historia los problemas que ésta causó se afrontaron con políticas orientadas a asegurar el mercado. Tras la independencia de España (1898) un tratado con EEUU permitió expandir la oferta de azúcar; después de la crisis de 1930 se evitaron los cambios estructurales que experimentaron otras economías latinoamericanas renovando ese tratado, y al inicio de la revolución se logró que la URSS y el CAME comprasen el dulce que dejó de adquirir EEUU. ${ }^{1}$ En 1990, sin embargo, no fue posible hallar clientes alternativos a Europa del este, lo que junto al fin de la relación que tenía con ella, provocó una dramática crisis. Después aparecía un nuevo socio, Venezuela, que proporcionó petróleo barato y las ayudas que otrora llegaban del bloque socialista, pero la recuperación ha sido débil y las perspectivas son inciertas.

La situación descrita, ya que la relación con Venezuela ha compensado en otros aspectos la que tenía con la URSS, pero no ofrece mercado para el azúcar, evidencia que el problema de la economía cubana ha sido el fin de su especialización y la incapacidad para construir una alternativa. Los estudios del tema, centrados en las políticas, apenas lo han abordado desde esa óptica, lo que se propone hacer en este artículo.

\section{La crisis de la revolución como cuestión de confianza}

Los pilotos dicen que un «aterrizaje del que se puede salir caminando es un buen aterrizaje, sólo que siempre he pensado que las compañías de aviación no piensan igual. En nuestro caso el piloto puede estar satisfecho, pero nosotros somos la compañía». Así describe Yoss la situación causada por el fin de la URSS y el modo de afrontarla:

1 Santamaría, 2002; 2011. 
La principal consecuencia ha sido una falta de confianza. [...Las medidas] no corresponden a un plan preconcebido, sino reactivo. Uno activo hubiera previsto que [...la URSS] tenía los pies de barro [...]. Durante 20 años la política ha sido [...] incoherente. En 1993 se abrió la iniciativa privada [...] porque no quedó más remedio, pero luego se trató de cerrarla [...] y hoy se vuelve a abrir. La gente dejó de creer en que el gobierno era capaz de satisfacer las necesidades y éste reconoció su incapacidad [...] El cubano está resolviendo como puede, sin un plan, igual que el gobierno, y esto no es más que el reflejo de la política. ${ }^{2}$

Entre lo mucho que se ha dicho de Cuba postsoviética hay pocas descripciones tan atinadas. «¿Qué significa período especial en tiempo de paz?», decía Fidel Castro cuando adivinaba ese final: «que debiéramos afrontar una situación de abastecimiento» equivalente a «lo que llamamos período especial en tiempo de guerra. No sería tan grave [...] porque habría ciertas posibilidades de exportaciones e importaciones, [...pero] debemos prever cuál es la peor situación [...y] bajo esas premisas se está trabajando». ${ }^{3}$

Desde entonces han pasado 22 años y en revista oficialmente autorizada, Temas,${ }^{4}$ un poeta del pueblo dice del trabajo realizado: «no estamos satisfechos», no ha habido un «plan» capaz de «prever» lo que pasaría, y tras dos décadas de «política reactiva», «aperturas porque no quedó más remedio» y «cierres», «la gente dejó de creer».

El período especial empezaba oficialmente en verano de 1991, poco después de anunciarlo Castro y poco antes de la disolución de la URSS, que ocurría en diciembre. Los problemas económicos eran ya graves y las expectativas nada alentadoras.

\section{De cómo cuando la revolución triunfó también se había dejado de creer}

El período especial fue el fin de la también especial relación de Cuba con la URSS y, lo más grave, de dos siglos de especialización económica en producir azúcar, debido a la imposibilidad de reemplazar al extinto

2 Yoss, 2011, 70.

3 Castro, 1990.

4 Reza su editorial: «se publica [...con el fin] de constituir un espacio para la reflexión [...] Su financiación ha sido provista mayormente por el Ministerio de Cultura», Temas, 1995. 
mercado socialista. ${ }^{5}$ Por eso, frente a los estudios que, en general, abordan el tema con enfoque de política, en las siguientes páginas se propone hacerlo en perspectiva histórica, atendiendo a continuidades y cambios, a la relación que quienes asumieron el poder en 1959 ha tenido con la especialización heredada, y a las oportunidades que tuvieron de modificarla o perpetuarla.

En 1959 Cuba era una de las economías latinoamericanas con mayor PIB per capita (gráfico 1) y la más equitativa. ${ }^{6}$ Sin embargo, entre esas grandes economías, también era la única que no había experimentado cambios estructurales tras la crisis de 1930. Como resultado su crecimiento era muy dependiente de la producción azucarera y su exportación a EEUU, que adquiría el $80 \%$.? $^{7}$

Igual que otras grandes economías latinoamericanas, Cuba tuvo que afrontar una creciente complejización social y conflictos resultados del efecto de las sucesivas crisis. Clases medias, campesinos y obreros, excluidos del poder por una elite agro-comercial, financiera y de líderes mambises, se organizaban, y tras la recesión de 1930, una revolución derrocaba al dictador Gerardo Machado en 1933. La economía se ajustó a las condiciones postdepresión y preservó su especialización gracias a acuerdos con EEUU y en el mercado azucarero mundial, que garantizaron cuotas de exportación suficientes para mantener un crecimiento similar al de los principales países latinoamericanos y financiar políticas distributivas que permitiesen restaurar el orden socio-político. Sin embargo esto se acompañó inicialmente de cierta diversificación, pero la industria azucarera mantuvo su ventaja comparativa, y la posibilidad de aumentar su producción tras el

5 La especialización tuvo su origen en las reformas del imperio español desde la década de 1760, que impusieron un proyecto económico-colonial basado en la producción de azúcar con esclavos, sobre todo tras la revolución de Haití (1791), el mayor exportador mundial entonces. Pero fue después de abolirse la trata y la esclavitud en Gran Bretaña (1808-1838) y del comienzo de la construcción ferroviaria en Cuba (1837) cuando progresivamente la industria del dulce acaparó los recursos potencialmente destinables a otras actividades y se conformó una estructura de oferta articulada en torno a ella. La especialización, además, fue creciente, se reforzó con las trasformaciones que experimentaron los ingenios para afrontar la abolición (1868-1886) y adoptar las innovaciones de la Segunda Revolución Industrial, tras la independencia de España (1898), por el fortalecimiento de la relación económica de la isla con EEUU, y debido a las posibilidades para expandir las exportaciones azucareras que supuso la Primera Guerra Mundial, y se consolidó con los acuerdos comerciales con que se afrontó la crisis de 1930. Santamaría 2002, 2011.

6 El porcentaje de los salarios en el PIB o la cobertura de sus pensiones $(63 \%)$ eran los más altos, su GINI (0,55), nivel educativo y sanitario de los mejores. Brundenius, 2009; Mesa-Lago, 1996; Thorp, 1998.

7 Thorp (ed.), 1999; Santamaría, 2002. 
inicio de la Segunda Guerra Mundial reforzaron la concentración de los recursos en ella. ${ }^{8}$

El principal problema económico de Cuba después de 1930 derivó de cómo se realizó el ajuste frente a la crisis. La posibilidad de aumentar la producción azucarera en los años siguientes perjudicó al resto de la oferta, causando problemas de crecimiento y financiación de las políticas sociales y una fuerte dependencia de la importación de bienes básicos. No se logró articular un proyecto económico sostenible ni mecanismos que compensasen las oscilaciones cíclicas de las exportaciones de dulce, y se recurrió a la deuda externa como alivio. Así ocurrió tras la Segunda Guerra Mundial o la de Corea, y las crisis ulteriores provocaron un recrudecimiento de los conflictos. ${ }^{9}$

A mediados de los años cincuenta el fin de una de esas fases alcistas azucareras provocó una crisis que afectó gravemente al nivel de vida. Se reforzaron los incentivos para otras producciones, pero no se logró un crecimiento que compensase a corto plazo las dificultades. Frente al aumento de la conflictividad un golpe de Estado de Fulgencio Batista suspendió las garantías constitucionales y mecanismos institucionales de expresión de la oposición y el descontento. Además la clase política se caracterizó por una galopante corrupción vinculada con las concesiones a empresas controladas por ella y por capital estadounidense, que también fueron objeto de movilizaciones sociales. ${ }^{10}$

En síntesis, parece que una explicación plausible del triunfo de la revolución es que se había dejado de creer en la capacidad de la clase política para resolver los problemas. La desconfianza alcanzó al propio Batista, que abandonó Cuba en enero de 1959, acuciado por un movimiento revolucionario y sin apoyos internos.

8 Marqués, 1994; Santamaría, 2002, 224.

9 Ver Alienes, 1950; Zuaznávar, 1988; Santamaría, 2011, 165, o los informes BIRF, 1951; CEPAL, 1958

10 Ver Toro, 1975; Ibarra, 1995, 250-88; Zuaznávar, 1988, 121; Santamaría, 2011, 170. Entre 1955-1957 disminuyó el consumo per capita de carne y la parte del gasto familiar dedicada a comida pasó de 40 a $57 \%$. La mejora en las viviendas fue evidente pero diferencial. En las ciudades el 87 $\%$ tenían luz, el 53 agua y el 34 eran insalubres, frente al 9, 2 y $75 \%$ en el campo, donde además sólo un $5 \%$ de las personas ingerían carne o pescado regularmente y un $11 \%$ leche, y el $80 \%$ eran dueñas o inquilinas de tierra, pero si eran de color únicamente el $50 \%$. Nelson, 1950; Censo, 1953; Pollit, 1967. 


\section{GRÁFICO 1}

PIB REAL PER CAPITA DE VARIOS PAÍSES AMERICANOS, 1913-1960

(\$ GARY-KHAMIS)*

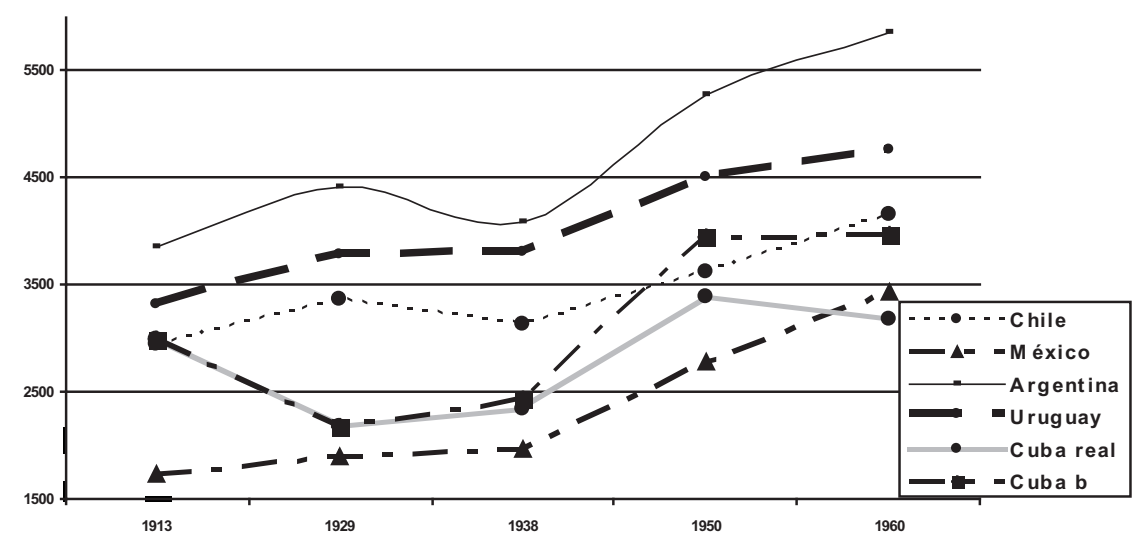

* Cuba b: estimado con el ingreso no exportador creciendo a la tasa máxima después de 1930 Fuente: Prados, 2007; Santamaría, 2000; MOxLAD, 2014; Latin Focus, 2014

Económicamente hablando el gráfico 1 confirma lo señalado. El PIB de Cuba había crecido como el de Argentina, Chile o Uruguay, pero en la década de 1950 sufrió una caída sin parangón. Y el principal problema fue la incapacidad de la oferta interna para compensar las oscilaciones de las exportaciones, pues si las actividades menos vinculadas con ellas hubiesen mantenido su crecimiento en el nivel máximo alcanzado tras la crisis de 1930, el PIB habría sido un 16 y un $25 \%$ mayor en 1950 y 1960.

\section{Y en eso llegó Fidel o la isla que se repite}

Y en eso llegó Fidel — canta Carlos Puebla-, llegó el comandante y mandó a parar. Castro, que había liderado la revolución en la sierra, ocupó el poder al huir Batista. La planificación centralizada con criterios políticos, de servicio social igualitario, empezó a regir enseguida la economía, pero sin modificar su estructura y problemas radicales. Y así sigue hoy, aunque tras el fin de la URSS ha dejado de ser azucarera e iniciado una crisis no resuelta por erráticas reformas. 
No es fácil evaluar lo sucedido desde 1959. Aparte de la insuficiencia estadística, el proceso está envuelto en debates ideológicos y no ha acabado. Antes de la revolución la economía dependía en exceso del sector externo, el azúcar y su venta a EEUU, y adolecía de problemas de financiación por no haber equilibrado su estructura productiva para compensar las crisis cíclicas del comercio exterior. Era difícil transferir los costes de esas crisis al trabajo y preciso atender progresivas demandas distributivas e importar bienes básicos, lo que afectaba a la productividad y crecimiento y se resolvía con desajustes fiscales y deuda, con impacto negativo en la inflación y el crédito, imprescindible para acometer las necesarias reformas, y terminó agravando los problemas y generando conflictos y desconfianza que impidieron sobrevivir al sistema socio-político.

Después de 1959 la economía mantuvo su dependencia comercial, del azúcar y un único cliente. Además la URSS aportó capital para costear el énfasis igualitarista, el efecto negativo de la especialización en la oferta interna y la merma de productividad que supuso abolir los incentivos laborales. La represión de la oposición se combinó con emigración y exilio, sobre todo a EEUU, y se puede hablar de una sociedad y economía cubana allí y otra en Cuba, con la que intercambia recursos humanos por remesas. Esos rasgos han sobrevivido a la URSS y también la necesidad de un socio que provea ayudas y petróleo barato, aunque ahora a cambio de servicios, no de azúcar, por lo que la sociedad está más sujeta a la voluntad del amigo, la Venezuela de Hugo Chávez y Nicolás Maduro, que determina qué importar, a qué precio y cuánto petróleo envía a la isla.

Desde 1990 a los problemas económicos se ha unido el deterioro de los logros sociales. La larga fase de bonanza mundial alcanzó también a Cuba, pero no resolvió esos problemas, y al acabar el propio Castro dudó de la supervivencia de su sistema: «el modelo cubano ya no nos sirve ni a nosotros». ${ }^{11}$ Glosando a Benítez Rojo, es la isla que se repite, o la revolución que la repite, aunque está por ver si es la hora final, como lo fueron 1898 o 1959. En 1987 un libro titulado así ganó el Pulitzer y han pasado 27 años. ${ }^{12}$

Mesa-Lago analiza desde hace años la economía cubana sin más peaje que la evidencia, lo que otorga a sus estudios una aceptación inmensurable en tema tan polémico. Sostiene que se ha caracterizado por alternar

11 Goldberg, 2010.

12 Benítez Rojo, 1989; Oppenheimer, 1992. 
ortodoxia y pragmatismo en respuesta a las situaciones que ha debido afrontar. ${ }^{13}$ La historia, empero, denuncia que la prioridad ha sido la ortodoxia y su dejación una estrategia de retorno. La revolución no fue socialista al principio, a su política colectivizadora replicó EEUU con un embargo que completó al declararse aquélla marxista-leninista en 1962 para acercarse a la URSS, acción-reacción según la lógica de la Guerra Fría. ${ }^{14}$ Desde entonces a la erosión del mercado como articulador económico-social, a las políticas igualitaristas, reforma agraria e industrialización, imbuidas de discurso antiazúcar, considerada causa de todos los males, se unió la implantación del modelo soviético de planificación centralizada.

Grandes zafras y el uso de recursos infrautilizados evitaron una crisis temprana, pero la diversificación apenas dio fruto a corto plazo y ésta se presentó en 1962, coincidiendo con un alejamiento de la URSS por haber excluido a Cuba de la negociación con EEUU en la crisis de los misiles. Siguió entonces un debate entre socialismo de mercado y modelo chino (condiciones subjetivas capaces de cambiar las objetivas), defendidos por Carlos R. Rodríguez y Ernesto Guevara. ${ }^{15}$ Castro dividió la economía entre ambos y la situación empeoró, ante lo cual optó por el segundo, aunque cambiando el discurso antiazúcar por azúcar para diversificar, ayudado por el establecimiento en 1963 de precios subsidiados en la URSS. Pragmatismo, pues, en el ciclo más idealista de la revolución, que terminaría imponiéndose con el plan de realizar una zafra de 10.000.000 de toneladas en 1970, e inauguraba su fase más exitosa. Aumentó la oferta de dulce, se modernizaron el cultivo cañero y los centrales y sus exportaciones se concentraron en el CAME. Aumentó la producción de otros bienes y el consumo. Se experimentó, en fin, un fuerte crecimiento fruto del incremento de la inversión y productividad de capital y trabajo, aunque partían de niveles muy bajos, y de la reducción del exceso de moneda, pero a costa de acumular deuda y déficits fiscales y en las balanzas comercial y de pagos, financiados con ayudas y petróleo barato soviéticos.

En 1985 los problemas económicos provocaban reformas en la URSS que acabarían con su extinción, ante las cuales, como en otras ocasiones, la respuesta del castrismo fue volver a la ortodoxia con el llamado Proceso de Rectificación, que se prolongó hasta 1990 y empeoró la situación. ${ }^{16}$

13 Mesa-Lago, 1985-2012.

14 «Segunda», 1962.

15 Rodríguez, 1978; Mesa-Lago, 1996, 37.

16 Mesa-Lago, 2003, 28. 
El cuadro 1 muestra que la evolución de la economía revolucionaria estuvo influida por los ciclos de política, pero siguió ligada al azúcar. Ante su primera crisis reforzó su especialización, lo que permitió recobrar en 1972 el PIB per capita de 1959, aunque el techo de oferta de dulce logrado entonces (8.500.000 toneladas), su pérdida de competitividad y la crisis del petróleo redujeron luego su crecimiento. La ayuda de la URSS, el crudo barato que enviaba a Cuba y que si no consumía le pagaba en divisas, y el aumento de las exportaciones mineras, permitieron evitar la depresión que asolaba entonces América Latina (gráfico 2). ${ }^{17} \mathrm{~A}$ cambio se reforzaron los lazos con Moscú mediante el envío de tropas a Angola y Mozambique, uno de los escenarios de la Guerra Fría.

La oferta de azúcar — y la política económica castrista — siguió respondiendo a los precios. Decreció mientras los internacionales estuvieron estancados en 3,2 centavos/libra y los soviéticos en 4,1; pero volvió a aumentar desde 1963, cuando la URSS los fijó en 6,1 permanentemente y Cuba recibió una media de 4 por sus exportaciones. ${ }^{18}$ La ayuda socialista, pues, reforzó la especialización de la economía insular con lo que hoy se llama precio justo. EEUU también había pagado un plus por el dulce, aunque sujeto a los cambios de mercado, de modo que entonces se lograba minimizar el efecto de éstos. Sin embargo surgieron otros problemas. Los centrales se modernizaron con tecnología soviética, pero la falta de competencia, el uso de trabajo voluntario, poco cualificado, y la dirección centralizada, mermaron la productividad. El esfuerzo que supuso la zafra de 1970 provocó una disminución en las de 1971-1972 (5.900.000 y 4.300.000 toneladas) y el rendimiento medio de $13 \%$ logrado hasta 1968 se redujo a 11 en $1970-1993 .{ }^{19}$

El azúcar siguió suponiendo el $80 \%$ de las exportaciones hasta 1990 y éstas se concentraron en el CAME (51 \% en 1960-1964; 80 en 19801989). Respecto a 1959 sólo cambio el destino (antes EEUU). Salvo minerales y petróleo reexportado, los otros bienes redujeron su porcentaje hasta 1979, sumando como máximo un $6 \%$, aunque luego aumentaron a $12 \%$. Sólo entonces disminuyó el de los alimentos y manufacturas en las impor-

17 La reexportación de petróleo creció de 40.000.000 \$ en 1975-1979 a 315.000.0000 en la década siguiente; las exportaciones mineras de 36.000.000 en 1960-1964 a 60.000.000 en 1955-1969, 170.000.000 en los años setenta y 330.000.000 en los ochenta. Mesa-Lago, 2003, 178; JUCEPLAN, 1977. Durante la crisis iniciada en 1973 los términos de intercambio mejoraron un $27 \%$ y el poder de compra de las exportaciones un 88, frente al -20 y -72 \% en América Latina. Maddison, 1988, 61.

18 Santamaría, 1994, 111.

19 Pérez-López, 1994, 71. 
taciones (de 20 a $13 \%$ y 22 a $16 \%$ ), pero el dinamismo de la oferta interna, la mejora del nivel de vida y los altos precios dispararon el del combustible (19 \% en 1970-1974; 33 en 1985-1989). El desarrollo industrial y la renovación de los centrales y transportes explican que la maquinaria preservase su proporción en un $33 \%$. Además el gasto que ello supuso superó siempre al ingreso, creció más que él en épocas de bonanza y decreció menos en las crisis, lo que acarreó un continuo déficit, que después de 1980 rebasó 1.770.000.000 \$ (cuadro 1) y no compensó el superávit con la URSS (2.770.000.000 en 1986-1990).

\section{CUADRO 1}

INDICADORES DE LA ECONOMÍA CUBANA (MEDIAS QUINQUENALES Y \% DE CRECIMIENTO)

\begin{tabular}{|c|c|c|c|c|c|c|c|c|c|}
\hline \multirow{2}{*}{ Años } & \multicolumn{2}{|c|}{ Población } & \multicolumn{2}{|c|}{ PIB per capita } & \multicolumn{2}{|c|}{ Azúcar } & Exportación & Importación & Balanza \\
\hline & Miles & $\%$ & $\$$ & $\%$ & Miles $t$ & $\%$ & \multicolumn{3}{|c|}{ Millones USD } \\
\hline 1960-64 & 7.360 & 3,0 & 3.116 & 1,2 & 5.229 & 0,7 & 603 & 737 & -134 \\
\hline 1965-69 & 8.206 & 2,3 & 1,810 & $-14,6$ & 5.300 & 0,3 & 662 & 1.053 & -391 \\
\hline $1970-74$ & 9.936 & 4,2 & 3.354 & 9,3 & 5.980 & 2,6 & 1.215 & 1.315 & -100 \\
\hline $1975-79$ & 9.580 & $-0,7$ & 3.635 & 1,5 & 6.660 & 3,0 & 3.101 & 3.403 & -302 \\
\hline $1980-84$ & 9.848 & 0,6 & 4.614 & 4,2 & 7.520 & 1,9 & 4.827 & 5.747 & -919 \\
\hline $1985-89$ & 10.360 & 1,0 & 5.010 & 1,6 & 7.600 & 0,2 & 5.512 & 7.789 & -2.277 \\
\hline 1990-84 & 10.756 & 0,8 & 3.060 & $-12,7$ & 6.180 & $-3,7$ & 2.780 & 3.220 & -440 \\
\hline 1995-89 & 11.030 & 0,5 & 2.711 & $-2,6$ & 3.800 & $-7,7$ & 1.620 & 4.200 & 2.580 \\
\hline 2000-04 & 11.222 & 0,3 & 3.326 & 3,7 & 3.300 & $-2,6$ & 1.630 & 4.140 & 2.470 \\
\hline 2005-09 & 11.400 & 0,3 & 5.467 & 7,8 & 1.300 & $-12,0$ & 3.000 & 5.360 & 2.360 \\
\hline
\end{tabular}

Fuente: PIB en USD Gary-Khamis y desde 2000 promedio de los cálculos PNUD, 1995-, Mesa-Lago, 2009; Brundenius, 2009; Santamaría, 2011; FMI, 2012; ONE, 2002-2008, de donde proceden los otros datos

El principal problema económico de Cuba, por tanto, siguió siendo la debilidad de su oferta. El plan azúcar para diversificar así lo reconocía, y como en otros momentos de su historia tuvo poco éxito. El ingreso agrario no exportador cayó del 18 al $13 \%$ del PIB en 1960-1980, aunque luego aumentó hasta $16 \%$. Creció, pues la renta también lo hizo, pero en general después de 1970, lo que indica que en la época de discurso antiazúcar 
su evolución fue peor. Las políticas colectivizadoras, la falta de incentivos laborales y la ineficacia de la dirección centralizada mermaron la productividad, la cabaña vacuna se estancó, la porcina y avícola disminuyeron un 60 y $12 \%$, la oferta de tabaco y leche un 29 y $50 \%$, y sólo mejoró la de arroz, cítricos y huevos (13, 27 y $259 \%)$.

La oferta agraria creció desde los años setenta gracias a un plan modernizador. El número de tractores aumentó un $16 \%$, su potencia un 25 , mejoró la eficiencia por la autorización de cultivos privados y mercados libres campesinos, pues apenas varió en las granjas estatales. La cabaña vacuna, monopolio de éstas, disminuyó en 1970-1898 un $14 \%$, pero se incrementó la de aves (105\%), cerdos (361), la producción de tabaco (31), huevos (45), arroz (67), leche (143) o cítricos (787 \%), aunque en una época de crecimiento económico y salarial, ${ }^{20}$ no bastó para atender el consumo y la importación de alimentos siguió aumentando (cuadro 1). De ella procedía el $54 \%$ de las calorías ingeridas por los cubanos. A pesar de que la inversión se elevó un $45 \%$ en 1975-1979, igual que el producto agrario neto, al eterno problema de Cuba (los centrales acaparaban el $50 \%$ del capital y la tierra) se unía el de la revolución: la productividad descendía un $12 \% .^{21}$

La industria no azucarera elevó su aportación al PIB de 48 a $55 \%$ en 1960-1989 gracias al aumento de la inversión económica neta de 11 a 17 \%, pero los centrales acapararon también la mayoría y apenas varió la estructura productiva, centrada en alimentos, textiles, tabaco y energía. Entre 1960-1970 cayó la oferta de comestibles y puros un 33 y $38 \%$ y se incrementó la de pescado, níquel, acero o electricidad $(242,185,122$ y $64 \%)$, pero de 1970 a 1979 se ralentizó el crecimiento de todas ellas, salvo la de energía y tejidos, que aumentaron 212 y $182 \% .22$

Las mejoras sociales fueron mayores: el Gini pasó de 0,55 a 0,22 entre $1958-1989,{ }^{23}$ el crecimiento demográfico se redujo desde 1975 por el escaso aumento vegetativo y la emigración. Son especialmente conocidos los éxodos de Mariel (1980) o los balseros (1994-) y se estima que hoy viven en el exterior el $28 \%$ de los cubanos (2.500.000), huida que ha servido de válvula de escape al descontento y la crisis, reduce la presión sobre la economía

20 La cuota de racionamiento de arroz per capita creció de 4 a 6 libras en 1969-1979 y se liberó la compra de carne, pescado o huevos. Mesa-Lago, 1996, 234.

21 Nova, 2009, 119.

22 Mesa-Lago, 1996, 227.

23 El siguiente mejor de América Latina era el de Costa Rica: 0,39. Brundenius, 2009, 45. 
y genera remesas, pero resta capital humano. El $15 \%$ de la población supera los 60 años y las pensiones son el $26 \%$ de las rentas de trabajo. ${ }^{24}$

La revolución logró pleno empleo virtual (desde 1980 el paro es de 4-8 \%) pero a costa de la productividad. Las mujeres están incorporadas al mercado laboral, son el $55 \%$ de la población, al inicio de los años ochenta ya copaban el $55 \%$ de los puestos y tantos cargos de responsabilidad como los hombres. ${ }^{25}$ Hasta su crisis en los noventa el sector azucarero acaparó un $20 \%$ del trabajo. Sin embargo la ocupación agraria ha disminuido velozmente (35\% en 1960; 5 en 2008) por la urbanización (75\%, como en las grandes economías latinoamericanas), y la distribución espacial de los habitantes ha variado poco, pues se controla políticamente.

Salud y educación han sido las prioridades. Entre 1959-1989 mejoraron la mortandad infantil (de 34 a $11 \%$ ), esperanza de vida (de 64 a 75 años), número de médicos y camas de hospital (de 0,9 a $3,3 \%$ y 4,3 a 5,3\%o) o el impacto de las enfermedades, salvo de las venéreas y vinculadas a dietas pobres. También se universalizaron las pensiones, sanidad y enseñanza. Gracias a campañas de alfabetización ésta pasó de 76 a $99 \%$, la matrícula en la escuela básica de 54 a $92 \%$ y en la secundaria y superior de 29 a $88 \%$ y de 4 a $23 \%$. Y tales avances han permitió reducir las diferencias sociales (entre negros y blancos, ciudades y campo) y evitar el trabajo y desnutrición infantil. ${ }^{26}$

Se puede decir, pues, que la revolución mantuvo a Cuba entre los países más igualitarios de América, con más avances que en ellos o que antes de 1959, pero a costa de expulsar población y libertades. Es cierto que en esos países el progreso democrático ha sido discontinuo, la situación actual no es ideal y muchas personas se han visto obligadas a dejarlos por causas económicas o políticas, pero ningún caso es hoy menos halagüeño que el insular. ${ }^{27}$ Aunque conserva altos niveles de equidad y acceso a la educación y sanidad, se han deteriorado desde 1989 y han crecido las desigualdades. El problema es que la ayuda soviética sostuvo un sistema productivo especializado, desequilibrado y generador de ingresos insuficientes para costear la política distributiva y que ésta ha afectado a la inversión, productividad y crecimiento más que antes de 1959.

24 Cuban Reserach Institute, 2011.

25 Luzón, 1989, 190.

26 Anuario, 2009. Según Fuente, 2007, la reducción de las desigualdades ya se estaba produciendo antes de 1959, aunque en un grado menor.

27 PNUD, 2009. 


\section{La política no cabe en la azucarera. Ya no nos quiere ni el pato Donald ni el osito Misha}

Así trovaba Carlos Varela en los años noventa, cuando la economía, si no colapsó, fue por una combinación de causas y azares que han permitido sobrevivir sin resolver los problemas. Sin el mercado, ayudas y petróleo soviéticos el PIB per capita cayó un 25 \% en 1989-1993; se recuperó la ortodoxia con el Proceso de Rectificación, poco eficaz frente a la contracción productiva debida a la falta de demanda y renovación tecnológica; ${ }^{28}$ aumentaron la oferta monetaria y el déficit, se derrumbaron las exportaciones e importaciones, y estas últimas volvieron a crecer luego sin que las primeras se reanimasen, generando 2.660.000 \$/año de desbalance en 1995-1999. Era el fin de dos siglos de especialización y de cómo se había construido y evolucionado.

La ayuda soviética a Cuba cesó en 1991 y el petróleo que le enviaba se redujo un 76 \% entre 1987-1996. La deuda insular era entonces la mayor per capita en América Latina. ${ }^{29}$ Se iniciaban reformas que permitían circular dólares y algún trabajo y cultivo privados. Los cuentapropistas pasaron de 0 a 100.000 hasta 1997 , los agricultores particulares a 200.000 y para vender su oferta se autorizaron de nuevo mercados libres, se potenció la biomedicina, fruto de los avances científicos del país, el turismo e inversión extranjera y se suavizó la relación con los exilados, que dejaron de ser gusanos para ser comunidad. Sin embargo no cesó el hábito del alternar ciclos ideológicos y pragmáticos y en 1997 se detuvieron las reformas y el progresivo crecimiento desde $1994 .^{30}$

Hay déficits estadísticos para medir el crecimiento económico de Cuba. Desde 1962 se estimó el Producto Social Global (PSG), como en la URSS, que excluye los servicios y tiene problemas de doble contabilidad. Los datos usados aquí intentan resolverlos mediante los cálculos de equivalencia entre PSG y PIB, computado a partir de 1986, pero sobrevalorado oficialmente,$^{31}$ y empleando una media de las cifras no oficiales (cuadro 1). Iguales problemas presentan otros indicadores de desarrollo, como el índi-

28 Entre 1989-1992 el producto agrario no cañero cayó un $65 \%$, disminuyó el rendimiento de todos los cultivos y el consumo per capita sufrió un fuerte deterioro. Nova, 2009, 37.

29 37.000.000.000 \$. Mesa-Lago, 2003, 174.

30 Mesa-Lago, 2006, 119-52.

31 Santamaría, 2011, 187; Brundenuis, 2009, 31. 
ce de PNUD, cuya información se ha modificado arbitrariamente, aunque Mesa-Lago propone correcciones que permiten ajustarlo. ${ }^{32}$

Pese a la precaución que merecen los datos (el PIB per capita oficial superaba en 2000 y 2009 un 25 y $100 \%$ la media de los cálculos alternativos, gráfico 2), es evidente que la economía cubana ha crecido desde 1999 gracias a la fase alcista internacional, la ayuda de Venezuela tras asumir Chávez el poder y las reformas, ${ }^{33}$ aunque después de alcanzar cierto nivel éstas se paralizaron y en 2003, con la Batalla de las Ideas, y el crecimiento se redujo del 13 al $3 \%$. Sin embargo los ciclones que asolaron la isla en 2005, cuyo efecto fue del $20 \%$ del PIB, obligaron a regresar al pragmatismo.

El cuadro 1 mostraba el aumento de las exportaciones desde mediados de la década de 2000, y también de las importaciones, lo que ha mantenido en 2.500.000 \$/año el déficit comercial. Cuba ha buscado nuevos socios y hoy envía el $22 \%$ de sus ventas a Países Bajos, otro 22 a Canadá, 19 a China y 6 a España. De Venezuela recibe el $27 \%$ de sus compras, de China $16 \%$, de España 10, de Alemania y Canadá 6 y de Italia, Brasil y EEUU 4. Pese al bloqueo el valor del comercio con EEUU creció de 4.000.000 a 320.000.000 \$ en 2001-2006 fruto de la distensión promovida por Bill Clinton y de las autorizaciones de George Bush para paliar el efecto de los ciclones. ${ }^{34}$

Tras su colapso la oferta de azúcar redujo su porcentaje en las exportaciones hasta el $5 \%$ en 2008 , y pese a su aumento en $433 \%$, minerales, pescado, fruta, fármacos y cemento, generan un $50 \%$ menos de ingreso que el dulce antaño. La balanza de capital no compensa la mercantil: se logró pasar de -380.000 .000 a 49.000.000 \$ en 2004-2006, pero luego retornó el déficit (-75.000.000 en 2008), y las reservas son insuficientes, aunque han crecido de 600.000 .000 a 4.200.000.000 $\$$ en 2004-2008. ${ }^{35}$

Las importaciones han variado menos. Ha crecido el porcentaje de los alimentos $(23 \%)$ - pues Cuba compra en el exterior el $84 \%$ de los que consume - y manufacturas, aunque durante el período especial cayó un $16 \%$. Maquinas y equipos mantienen un $30 \%$ y el petróleo, que representa un 25 , ha reducido algo su proporción por el aumento de la oferta interna y el suministro de Venezuela, que en 2008 vendía el barril a la isla a 28 \$

32 PNUD, 1995-; Mesa-Lago, 2003; 2009.

33 Ver Carranza et al., 1995; CEPAL, 2000; Pérez-Villanueva (ed.), 2004; Espinosa, 2011.

34 Anuario, 2007-2012; Domínguez et al., 2011.

35 Anиагіo, 2009. 
(el precio de mercado era 147). Esto es lo que ha permitido la supervivencia económica de la revolución, junto a la ayuda del país andino que en esa fecha sumaba 9.405.000.000 \$ - cifra superior a la que recibía de la URSS- (7\% por el bonus del crudo, $62 \%$ como pago de 40.000 médicos, maestros y técnicos insulares y $32 \%$ por inversiones en proyectos) gracias a los cual en 2007 la balanza de capital entre las dos naciones reportaba a Cuba 8.200.000\$. ${ }^{36}$

La caída del PIB desde 1990 permite estimar que Cuba vivía un $12 \%$ por encima de sus posibilidades gracias a la ayuda soviética. La de Venezuela es mayor, pero el nuevo socio ya no es su mercado, le provee servicios sanitario-educativos en vez de los militares que prestó a la URSS y la asimétrica relación sigue estando justificada por la ideología y sujeta a la voluntad del amigo, que podría prescindir de esos servicios y dejar a Cuba sin alternativas para obtener el capital y petróleo que recibe a cambio. La actual crisis mundial, la caída del precio del crudo, el enorme déficit fiscal de Venezuela y los conflictos que sufre tras la muerte de Chávez no son buenas expectativas. ${ }^{37}$

La inversión global, tras caer desde 1990, aumentó hasta el $12 \%$ del PIB en 2009, inferior al $26 \%$ que precisaría un crecimiento sostenido. ${ }^{38} \mathrm{La}$ inversión extranjera creció de 2.100 .000 .000 a 2.500.000.000 \$ en 20002009 y la formación bruta de capital de 5 a $9 \%$ del PIB. La inflación ronda el $4 \%$, el déficit fiscal $24 \%$, el cambio es de 24 pesos $\$$, pero desde 1994 hay dos monedas (bienes importados y considerados prescindibles se pagan en CUC, equivalente al dólar, y se gravan hasta un $300 \%$ ad valorem) lo que perjudica la productividad y las exportaciones. Los términos de intercambio han empeorado ${ }^{39}$ y se mantuvo el pleno empleo a costa de ineficiencia y sobreocupación. Eso es lo que significa vivir por encima de las posibilidades, con ayuda de una asociación que puede quebrar, un gasto en 2007 de $36.730 .000 \$$ con ingresos de 35.010.000, que proceden de impuestos indirectos (el $56 \%$ del consumo y remesas en divisas), y una deuda cuyo servicio es el $20 \%$ del PIB,${ }^{40}$ pues el embargo y la falta de

36 Anuario, 2008.

37 Mesa-Lago, 2011, 42; Vidal, 2014.

38 Pérez-Villanueva, 2008, 49.

$3953 \%$ desde 1989, Rodríguez, 1999; Vidal, 2014.

4016.600 .000 .000 \$, que han disminuido con condonaciones, en $2012-2014$, del 80 y $70 \%$ de la contraída con Japón y México (1.400.000.000 y 500.000 .000 \$). Otros 32.000 .000 .000 \$ debidos a la URSS han sido reducidos a 3.300 .000 .000 en 2013 por el gobierno ruso. Mesa-Lago, 2009, 51; «Rusia», 2014. 
crédito de organismos internacionales obligan a depender de préstamos a corto plazo al $22 \%$ de interés. ${ }^{41}$

El embargo se publicita como causa de todos los males. Su efecto se estima en el $140 \%$ del PIB de 2008, 96.000.000.000 \$. ${ }^{42}$ Es grande, pero también hijo de la revolución y como tal deben restársele las ayudas de la URSS y Venezuela (70.000.000.000 \$). Aún así es el $30 \%$ del PIB y ofrece una idea de los costes económicos del castrismo. Las remesas exteriores, unos $900.000 \$ /$ año, están sobrevaloradas ideológicamente, pues representan sólo un 1,4\% del PIB, 90 \$ per capita, frente a los 208 que los emigrantes mexicanos envían a su país, aunque son fuente insustituible de divisas y proporcionan acceso a ellas al $60 \%$ de los cubanos.

El embargo se reforzó en los peores tiempos para la economía de Cuba, con las leyes Torricelli (1992) y Helms-Burton (1996), que prohibía a los estadounidenses realizar negocios con ella y restringía las ayudas públicas y privadas, ampliada en 1999 para impedir a filiales de firmas norteamericanas comerciar por más de 700.000.000 \$/año con la isla. No obstante desde 2000 se han relajado con permisos al envío de comida y medicinas, sobre todo en época de huracanes, y la reciente liberalización por Barak Obama de los viajes y giro de dinero al país caribeño de los oriundos cubanos en EEUU. ${ }^{43}$

La ONU ha votado 22 veces contra el embargo, sus opositores señalan que perjudica a la población menos favorecida, que el castrismo lo usa como prueba de la intención de EEUU de ingerir en la soberanía de Cuba, y por eso ha solido responder negativamente a las ofertas de distensión - como ocurrió en 1996 con las de Clinton- o dudando de su certeza. ${ }^{44}$ Para mantenerlo se alega que dificulta el desempeño económico insular y la presión a su favor de los cubanos nacionalizados estadounidenses, con gran poder financiero y político, sobre todo en Florida. No obstante ésta ha ido relajándose y un $60 \%$ de aquéllos se muestran hoy partidarios del diálogo, lo que puede ayudar a poner fin al bloqueo, junto al hecho de que se estima que sólo en exportaciones supone pérdidas de 200.000.000 \$/año para EEUU, y que una mayor exposición a la competencia internacional aceleraría los cambios en el país caribeño. ${ }^{45}$

41 Brundenius, 2009, 42; Anuario, 2008.

42 Embargo, 2009.

43 Pérez-Stable, 2010; Domínguez et al., 2011.

44 Clinton apoyó la ley Helms-Burton tras el derribo por cazas cubanos de dos aviones que buscaban balseros en el estrecho de Florida. Vicent, 1997; «Fidel», 2009.

45 González, 2007; Pérez-Stable, 2008; «Elite», 2014. 
Las relaciones con la UE, segundo socio comercial de Cuba, fuente principal de inversiones y del $33 \%$ de sus turistas, se reforzaron con la apertura de una delegación en la isla en 1993, que desde entonces ha financiado programas de cooperación económica por 133.500.000 \$. En 1996 se supeditaron al avance en el respecto a las libertades y derechos humanos con la llamada Posición Común y en 2003 fueron suspendidas por el país caribeño. ${ }^{46}$ Sin embargo desde 2008 han recibido nuevo impulso y en 2014 el gobierno habanero afirma «acoger con satisfacción» una oferta europea para relanzarlas. ${ }^{47}$

El aislamiento de Cuba, pues, se alivia lentamente. La posición de la UE, la supresión en 2009 de su expulsión de la OEA en 1962, la reunión de la CELAC en La Habana en 2014, las condonaciones de deuda, las inversiones de Brasil en el puerto de Mariel, aeropuertos e ingenios, cifradas en 1.000.000.000 \$, y el envío de médicos insulares a ese país, responden a las oportunidades de negocio, pero también al ánimo de apoyar las reformas recientes y una transición política. La relación con EEUU parece moverse en igual sentido, incluso se piensa que la colaboración del gobierno cubano para resolver los actuales conflictos en Venezuela ayudaría a eliminar el embargo. ${ }^{48}$

Además Cuba ha intensificado su relación, considerada estratégica, con otros países socialistas. En 2013 firmó un protocolo de colaboración e intercambios con Corea del Norte. En una visita reciente al país caribeño, el primer ministro de Vietnam, principal provedor de arroz de la isla y cuyas empresas realizan prospecciones petroleras en sus aguas, ha acordado con Raúl Castro reforzar la colaboración mutua y el comercio, que ha crecido un $50 \%$ en 2013 y supera los $500.000 .000 \$ .^{49}$

Con China la relación es más importante. Su comercio con Cuba superó en 2010 1.800.000.000 \$ y en 2011 se firmó un acuerdo para que firmas del país asiático, que explotan hidrocarburos en la isla y rehabilitan refinerías en Cienfuegos -inversión valorada en 6.000.000.000 \$realicen nuevas prospecciones petrolíferas. La colaboración chino-cubana se materializó también en la creación de la empresa mixta científico-tecnológica Biotech Pharmaceutical y de una comisión intergubernamental en

46 Delegación, 2014; Santamaría y Lillo, 2009: 297.

47 «Cuba», 2014.

48 Malamud, 2014; «Brasil», 2014; Navatón, 2014.

49 «Azúcar», 2013; «Cuba», 2014. 
2013 para ofrecer crédito al país caribeño y asesorar sus reformas económicas. ${ }^{50}$

Junto a las remesas, ayuda venezolana y cooperación al desarrollo, ${ }^{51}$ turismo e inversiones son las fuentes de divisas de Cuba. El primero pasó de 101.000 vistas/año y 40.000 .000 \$ de ingreso en la década de 1980 a 1.700 .000 y $19.000 .000 \$$ en 2000 . Tras el $11 \mathrm{~S}$ su progreso se estancó, pero hoy la isla recibe 2.800 .000 personas anuales, y aunque la renta que generan ha crecido en menor proporción, supone un $20 \%$ del PIB. El sector ha recibido grandes inversiones, sin embargo no completa su oferta, es deficitario en servicios, depende en exceso de las importaciones, lo que merma su efecto multiplicador, y se ve perjudicado por la escasez de viajeros de EEUU, debido al bloqueo, cuya cercanía y poder adquisitivo supondrían un gran estímulo. ${ }^{52}$

La inversión extranjera es pequeña, se centra en actividades solventes, debe ser autorizada y controlada por el Estado y limitarse a empresas mixtas que no fijan los salarios ni incentivos laborales, potestad del gobierno, que cobra los sueldos y retiene su mayor parte. Por eso y por el cierre de varias de las 400 firmas con participación foránea que había en Cuba al declararse que el país sólo tenía interés en grandes inversiones en sectores estratégicos, se redujo un $22 \%$ entre 2000-2007. En 2008 entraban la isla por esa vía 11.240.000.000 \$ y salían en concepto de beneficios 4.138.000.000.53

Pese a lo dicho, el capital colocado recientemente en Cuba por Brasil, China y otros países — por ejemplo 5.000.000.000 \$ para rehabilitar refinerías en Matanzas- podría triplicar la inversión extranjera en breve. ${ }^{54}$ Aprovechar esto y las expectativas comerciales con dichos socios, la UE, incluso EEUU, sin embargo, requeriría un notable aumento de la oferta y competitividad de los bienes y servicios insulares.

Con tales datos los análisis suelen coincidir en que poco variará mientras dure el castrismo. En 2006 Fidel pasó el poder a su hermano, pero ni eso ni el cese en 2009 de los dirigentes más antiguos supuso cambios

50 Vicent, 2011; «China», 2013.

51 Estimada en 87.000.000 \$. Banco Central, 2009.

52 Anuario, 2009. Pese al embargo, 400.000 cubano-estadounidenses y 98.050 norteamericanos viajaron Cuba en 2012 (25\% más que en 2011), cifra que podría crecer, superar con holgura el 1.000 .000 que llega de Canadá y generar un aumento del $35 \%$ en el ingreso turístico y del $7 \%$ en el PIB. Cancio, 2013.

53 Mesa-Lago, 2009, 48.

54 «China», 2013. 
significativos, aunque quizá su inmovilismo es la clave de supervivencia del régimen hasta ahora, su constante vuelta a la ortodoxia y evidencia de que abandonarla era sólo una estrategia de retorno, lo que ha sido factible gracias a férreos mecanismos de control, aún operativos, cuya señera son los Comités de Defensa, formados en cada barrio y teóricos instrumentos de la democracia de base. ${ }^{55}$

Mientras, los ciclones y la crisis mundial frenaron el crecimiento y el problema sigue siendo la debilidad de la oferta interna, ya sin azúcar que la explique, un igualitarismo difícil de financiar, acudir para ello a la ayuda exterior sin dejar de acumular deuda y déficit, la baja productividad de capital y trabajo que suponen la dirección centralizada, ausencia de incentivos laborales y control de los beneficios; en fin, la falta de libertad económica. Mesa-Lago evalúa el desempeño de 84 indicadores desde 1959 y prueba que, en general, mejoraron desde la década de 1970, sufrieron en fuerte caída en la de 1990 y no se ha recuperado. La actividad productiva ha sido la peor parada (cuadro 2)..$^{56}$

El salario real ha caído un $75 \%$ desde 1989, no alcanza para satisfacer las necesidades básicas y la cuota de racionamiento apenas cubre una semana al mes. El paro ha disminuido de 8 a $2 \%$ a costa de la productividad. ${ }^{57}$ Las tasas de alfabetización y escolarización primaria y secundaria $(99,95$ y $87 \%)$ se han mantenido altas y no pueden crecer mucho. Si ha aumentado la matrícula universitaria de 23 a $88 \%$, aunque hay una gran desvinculación entre enseñanza superior y mercado laboral. Han mejorado la mortalidad infantil (de 11 a 5,3\%o), el número de médicos (de 3,3 a $6,4 \%$ ) o la esperanza de vida (de 75 a 78 años), pero hay menos camas de hospital per capita, han empeorado la mortandad maternal y la vinculada a enfermedades venéreas y dietas pobres. Déficits persistentes de la revolución, como vivienda o acceso a nuevas tecnologías, se han agravado o corregido poco, en el último caso debido también al control sobre la información..$^{58}$

55 Ver Thomas et al., 1985

56 Mesa-Lago, 2009, 41.

57 Según Sánchez y Triana, 2008, 157, un $35 \%$ de los trabajos son innecesarios.

58 Los ciclones han agravado el deterioro de la infraestructura de agua potable y saneamiento. El número de viviendas creció poco (de 665.000 a 780.000 en 1960-2013) y se han deteriorado sus condiciones. El acceso a Internet o a móviles ha mejorado con las autorizaciones para comprar equipos, pero la cantidad de internautas aumentó sólo de 6.000 a 12.000 en 2000-2001 y el de servidores de 15.000 a 34.000 en 2004-2005. Mesa-Lago, 2009, 59. 
ANTONIO SANTAMARÍA GARCÍA

CUADRO 2

OFERTA CUBANA DE ALGUNOS PRODUCTOS

\begin{tabular}{|l|r|r|r|r|}
\cline { 2 - 5 } \multicolumn{1}{c|}{} & \multicolumn{2}{c|}{ Toneladas/1.000 habitantes } & \multicolumn{2}{c|}{ Miles } \\
\cline { 2 - 5 } \multicolumn{1}{c|}{ Níquel } & 1989 & 2007 & 1989 & 2007 \\
\hline Petróleo & 4 & 7 & & \\
\hline Gas & 68 & 248 & & \\
\hline Acero & 30 & 108 & & \\
\hline Cemento & 322 & 158 & & \\
\hline Abonos & 85 & 12 & & \\
\hline Jabón & 3 & 1 & & \\
\hline Textiles $\left(\mathrm{m}^{3}\right)$ & 21 & 2 & & \\
\hline Calzado & & & 1 & 0,2 \\
\hline Puros & & & 29 & 36 \\
\hline Huevos & & & 245 & 202 \\
\hline Reses & & & 465 & 337 \\
\hline Cerdos & 14 & 4 & & \\
\hline Aves & 18 & 6 & & \\
\hline Leche & 4 & 4 & & \\
\hline Pescado & 97 & 31 & & \\
\hline Tabaco & 3 & 0,4 & & \\
\hline Cítricos & 50 & 39 & & \\
\hline Café & & & & \\
\hline Arroz & & & & \\
\hline
\end{tabular}

Fuente: Mesa-Lago, 2009

Entre 1989-2007 empeoró también el Gini de 0,25 a $0,41^{59}$ y el consumo calórico per capita y el coste de la canasta básica creció un $113 \%$. Las desigualdades han aumentado con las reformas, que favorecen sobre todo a la elite política y rentas altas, que pueden comprar en divisas o adquirir los bienes tecnológicos autorizados. Los blancos reciben 121 \$/persona de remesas exteriores, los no-blancos 35, el $3 \%$ de las cuentas acapara el $46 \%$ de los depósitos y los mayores de 60 años son los que sufren peores condiciones.

59 Brundenuis, 2009, 33. 
Raúl Castro aplicó un plan de fomento productivo y sustitución de importaciones que dio algún fruto, sobre todo con la oferta de leche y frutas, tras dejar un $60 \%$ en manos privadas, pero la falta de abonos, insecticidas y tecnología, que afecta también al transporte, ${ }^{60}$ frenan el desarrollo. No obstante por ello Cuba es el único país que cumple los requisitos de crecimiento agrario sostenible. ${ }^{61}$

El gráfico 2 compara el del PIB de Cuba con el de las grandes economías latinoamericanas y muestra cómo ha empeorado su posición. ${ }^{62}$ Usando datos oficiales, de haber crecido igual que la media de aquéllas, en 1970 hubiese sido un $35 \%$ más alto, en 1990 un $6 \%$, lo que quizá es un coste pequeño por los avances sociales y en equidad, pero al lograrse éstos con fuerte dependencia de factores que escapaban a su control y que acabaron desapareciendo, dos décadas después tales costes se elevaban al $9 \%$.

Los indicadores productivos dificultan aceptar el crecimiento estimado oficialmente. Los datos usados aquí parecen más reales y sólo teniendo en cuenta el mantenimiento de una sociedad de ayuda exterior que hasta 1990 fue comercial, ideológica y subvencionadora, y desde entonces subvencionadora e importadora de servicios. Tales datos permiten estimar el coste de la revolución en un 40-45 \% del PIB actual, aunque sin olvidar la precaución que ameritan las estadísticas.

Hay muchos estudios del tema y no es asunto de este artículo, pero debe señalarse que la situación descrita no pude explicarse sin atender a factores socio-antropológicos y de psicología política. La economía informal generaba en 1994 el 29 \% del PIB de Cuba y durante el período especial se encargó de prover lo que el Estado dejó de satisfacer. Con las reformas afloró una parte, aunque en las épocas de retorno a la ortodoxia, aumento de prohibiciones o impuestos volvió a sumergirse. Se calcula que antes de las recientes medidas aperturistas ocupaba a 350.000 personas $-8 \%$ de la

60 La flota de autos, pequeña y obsoleta, ha mejorado con la importación de vehículos, normalmente usados, para transporte colectivo y de mercancías. Además se han cerrado 6.000 de los $11.000 \mathrm{~km}$ de ferrocarril, la mayoría azucareros en desuso, y en el resto la infraestructura y servicio son precarios. De los $61.000 \mathrm{~km}$ de carretera, el $90 \%$ precisan mejoras. ONE, 2008.

61 Huella ecológica de 1,8 ha/hab y alto desarrollo humano: 0,8 (PNUD, 1995) aunque se ha indicado que los datos son poco fiables.

62 En 1998 el PIB de Cuba era un $8 \%$ del estadounidense; la media latinoamericana un 21. Prados, 2007. La crisis actual afectó poco al principio, pues su situación era difícil de empeorar. En 2009 la oferta agraria creció un 4,5\%, la del transporte 4,6 y la de servicios 4, y aunque apenas mejoró la comercial y la industria cayó un $25 \%$, al ser una economía cuyo sector terciario genera el $78 \%$ del PIB, el secundario $11 \%$ y el primario 5, la recesión tuvo un impacto inicial leve. Sin embargo ésta es básicamente financiera y debido a las dificultades de dicha índole que sufre Cuba, el efecto posterior ha sido severo. FMI, 2012. 
población activa-, muchas más completaban con ella sus ingresos, y Financial Times estimaba que en 1997 duplicaba en valor a la economía legal y proporcionaba productos equivalentes al $26 \%$ del gasto familiar. ${ }^{63}$ Junto a las remesas, ayuda exterior, trabajo en firmas extranjeras y válvula de escape que suponen exilio y emigración, esto ha representado alivio para la subsistencia de los cubanos, no obstante también ha aumentado las desigualdades, pues no todos tienen igual acceso a esas rentas, empleos u opciones de salida, que además se han usado como medio de fidelización de la elite política y económica, y Fidel Castro reconocía en 2005 que la corrupción consiguiente era el principal peligro para la revolución. ${ }^{64}$

\section{GRÁFICO 2}

PIB REAL PER CAPITA DE VARIOS PAÍSES AMERICANOS, 1960-2009*

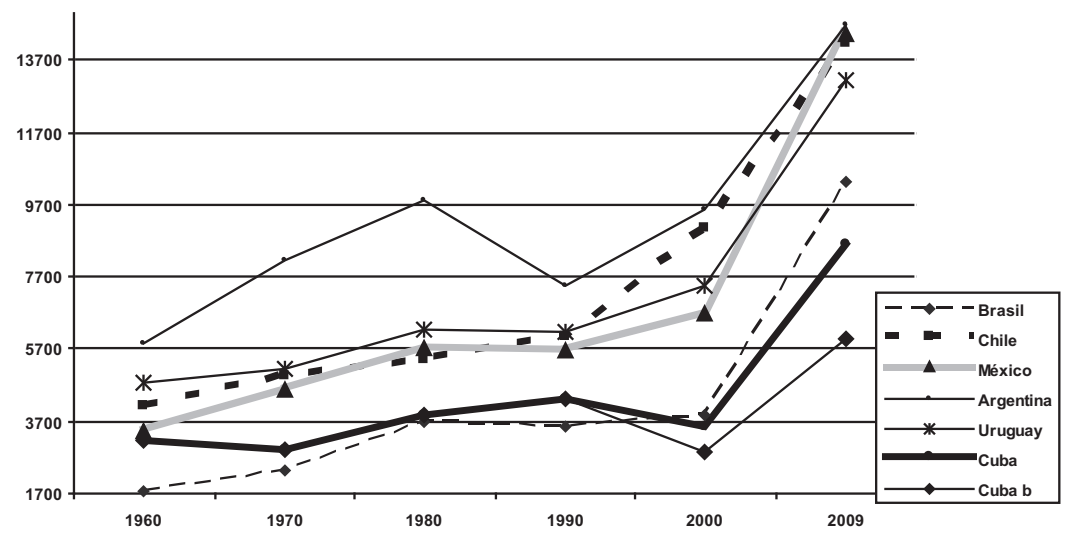

* Cuba b: media de los cálculos no oficiales 2000-2009. Fuente: gráfico 1

Los factores citados, la persistencia de políticas asistenciales, el mayor respeto de Raúl Castro - sin el carisma de Fidel- por las instituciones y atención a las necesidades básicas, o sus concesiones, como la excarcelación de varios disidentes ${ }^{65}$ el control ideológico-social, de la opo-

63 Pérez-López, 1995; «Sector», 2012.

64 Iñiguez, 2006; Díaz-Briquets y Pérez-López, 2006; Morales, 2010.

65 Pérez-Stable, 2014, 4. 
sición, el embargo de EEUU y la ayuda exterior, coadyuvan para que la actual situación de Cuba no haya quebrado la idea de plaza situada, el sentimiento antiimperialista con que se inició la revolución, alentado por la actitud norteamericana hacia la Venezuela de Chávez o Bolivia de Evo Morales. Colabora también a entender el inmovilismo social el temor al desembarco en la isla de los exiliados, de consecuencias difíciles de prever, pese a su reciente moderación, ${ }^{66}$ y que tantas veces ha usado el castrismo a su favor. Colaboran, asimismo, la experiencia poco deseable de Europa del este y de muchos países latinoamericanos en sus transiciones democráticas y aperturas a la economía de mercado. ${ }^{67}$ Además, aunque en tan poco espacio no es posible analizar tantos asuntos, el papel asistencial y dialogante que viene ejerciendo la Iglesia Católica y de otras confesiones en la isla y esa misma actitud defendida por parte de la disidencia interna, favorecen que las posiciones no se hayan radicalizado ni generado fuertes conflictos y ofrecen espacios de conciliación. ${ }^{68}$

\section{Corolario de batallas o contrapunteo revolucionario de la economía y las ideas}

Ante la grave situación causada por la crisis mundial, Raúl Castro convocó en 2010 el VI Congreso del Partido Comunista, aplazado desde 2002, por sorpresa - práctica habitual del castrismo - y durante una visita de Chávez para celebrar 10 años de alianza cubano-venezolana. La reunión tendría un único objetivo, reformar la economía, formular propuestas con que suprimir un $25 \%$ del empleo público, permitir contratar a particulares y más trabajo por cuenta propia como alternativa. Se anunciaban reformas tributarias y que el Banco Central apoyaría con crédito la iniciativa privada, pero nada se adelantaba sobre si habría más libertad económica, en las inversiones nacionales, extranjeras y de los cubanos en el exterior, o la disposición de los beneficios. La Batalla Económica, nombre dado al nuevo ciclo revolucionario se imponía a la Batalla de las Ideas, aunque esgrimiendo como razón «no caer por el precipicio». ${ }^{6}$

66 Pérez-Stable, 2008, (ed.), 2007.

67 Alonso, 2006; Martínez, 2006.

68 Ver Castro, 2012 o la revista Espacio (2005) acerca de la Iglesia y sobre la disidencia, Proyecto, 2004 o el blog Sánchez, 2014.

69 Santamaría, 2010. 
En 2011 se celebró el congreso sin aclarar suficiente las reformas económicas y laborales. A cada cual según su trabajo — se dijo-, había que eliminar burocracia, se abolía el requisito de militar en el PCC para ocupar cargos y se limitaba el ejercicio de los mismos a 10 años, pero a la vez se consagraba a líderes octogenarios (Raúl Castro, José R. Ventura) y militares y dirigente tradicionales copaban el $60 \%$ de buró político. Además se reconocía la falta de relevos y necesidad de formarlos, aunque sin explicar los medios en un régimen unipartidista y sin democracia efectiva, como indica la exclusión del debate congresual de 48 propuestas de comités locales referidas a temas de oposición y reformas, según Raúl Castro, porque defendían «la concentración de la propiedad».

La reforma se llamó actualización del modelo, preveía suprimir 1.500.000 empleos públicos, autorizar más oficios cuentapropistas, la compra y alquiler de viviendas y autos, entregar tierra para mejorar la oferta y productividad agraria y reducir la importación de alimentos ${ }^{70}$ por lo que es la mayor actualización aplicada por la revolución. Según Rolando Anillo, de Fowler \& Co., empresa de cubanos en EEUU, esto podía desencadenar un gran movimiento de capital, pues «hay gente con dinero que empezará a adquirir y reparar casas». Además en tres meses se dieron 200.000 licencias para 178 trabajos permitidos y se estima que hoy en Cuba hay 455.000 cuentapropistas —en 2011 eran 157.000 — y su aportación al PIB ha aumentado un $2 \% .^{71}$ Ahora bien — dice Mesa-Lago- el cambio no es comparable al de China o Vietnam, donde se otorgó el suelo al campesino, no su usufructo, y una reforma y liberalización efectiva de precios y mercado elevó velozmente el nivel de vida, mientras las liberalizaciones parciales en Europa del Este fracasaron. En la isla se han entregado 1.200.000 hectáreas de terreno público ocioso con parcos resultados hasta ahora a falta de otras medidas: derecho de propiedad, disponibilidad de crédito y mercados o acceso a la tecnología. ${ }^{72}$

Oppenheimer cree que el congreso fue para comprar tiempo. Los líderes son viejos, no implementarán la reforma, pero esperan que se les reconozca haberla iniciado sin arriesgarse a cambios que «podrían llevarlos a prisión». ${ }^{73}$ Así anunciaban la promoción de la autogestión empresarial, inversión extranjera, disposición de crédito, reforma fiscal o la esperada

70 «Congreso», 2014.

71 «Cuba», 2012; «Trabajo», 2014.

72 «Contradicciones», 2011; Mesa-Lago, 2011.

73 Oppenheimer, 2011. 
unificación monetaria, pero avisando que las resoluciones del cónclave son orientativas, no leyes. Además, vicio habitual del castrismo, a la vez que se discutía esto, se dedicaban horas a debatir, por ejemplo, la necesidad de reparar las ollas arroceras, tema vital para los cubanos, pero poco adecuado para el máximo órgano de representación de su único partido. En fin, en él se dijo también que se mantendrían la planificación centralizada y propiedad estatal de los medios productivos, aunque con más autonomía en las empresas públicas, fomento de las cooperativas, pequeños empleadores, agricultores privados y cuentapropistas como medio de elevar la eficiencia, y se aseguró que prevalecería la igualdad de derechos y oportunidades, pero sin incurrir en igualitarismo y que, garantizados los principios, esperaba un arduo trabajo legislativo.

Es pronto para evaluar la reforma, prever si reanimará la economía y salvará la revolución. La victoria electoral de Chávez en 2012 alivió el temor a cambios en Venezuela, aunque entonces ya se temía que su salud acabaría con su vida. El dirigente ha dejado al país en una precaria situación y su sucesor se enfrenta a una creciente conflictividad social, pese a haber sido refrendado en las urnas. Según Mesa-Lago el $20 \%$ de la actividad económica en Cuba depende de Venezuela, que le envía 96.000 barriles de petróleo/día, genera un comercio bilateral de 6.000.000.000 \$/año y es una fuente de crédito con pocas restricciones, pues lo que la isla no puede pagar se transforma en deuda. Hay quien piensa que el fin de tales ayudas sería un acicate para las reformas si hay voluntad de aprovecharlo, pero también que si se suspenden súbitamente provocarían un colapso que podría derivar en una situación insostenible para la dirigencia revolucionaria y la dejaría sin recursos con que reaccionar a corto plazo. En contra de dicha posibilidad juega el hecho de que el gobierno venezolano, aunque cambie próximamente, se hallaría en una grave tesitura si tuviese que prescindir rápidamente de los médicos, maestros y técnicos insulares que prestan servicio en la nación andina. ${ }^{74}$

Vidal estima que el cese de la relación con Venezuela provocaría una caída del 7,7 \% del PIB de Cuba en un cuatrienio y del $35 \%$ en la inversión y un deterioro del $20 \%$ en los términos de intercambio. Además generaría tensiones, pues la isla no se ha recobrado de la crisis desatada por el fin del URSS, que se afrontó con ajustes inflacionarios, a los que no es posible recurrir ahora al no haberse recuperado el poder adquisitivo. ${ }^{75}$

74 Tamayo, 2013.

75 Vidal, 2014. 
La salud de Fidel Castro es precaria y se ignora qué efecto tendrá su muerte, aunque en este caso hay más tiempo para preverlo y Raúl Castro lleva ocho años en el poder. Mesa-Lago acaba de editar un libro sobre él, y no obstante es relativamente optimista en sus conclusiones, no quiebra la idea de que la situación de Cuba no variará significativamente hasta que cambie efectivamente su dirección. ${ }^{76}$ En febrero de 2013 se nombró primer vicepresidente del Consejo de Estado a Miguel Díaz Canel. El nuevo princeps sustituiría al presidente si le ocurriese algo y este último ha afirmado que, si su salud lo permite, sólo estará al frente del país hasta 2018. Independientemente de que es un tiempo suficiente para que ocurran muchas cosas, en contra o a favor del sucesor, su figura no es fácil de evaluar. Tiene 52 años, no pertenece a la vieja guardia revolucionaria, pero ha ostentado cargos relevantes (ha sido ministro) y lleva tiempo colaborando estrechamente con Raúl Castro. Además es considerado hombre ortodoxo, sin embargo progresar en la política insular precisa de tal consideración, por lo que es difícil saber qué piensa realmente o cómo actuará si ha de enfrentarse a responsabilidades mayores.

Mientras esto sucede en la alta política, se han ido efectuando las reformas previstas. Tras el congreso del PCC se han publicado más de 300 medidas. Entre las últimas, por ejemplo, se ha convertido Correos en empresa privada, se ha diseñado un plan de reorganización del mercado mayorista, monopolio estatal, con el fin de mejorar el abastecimiento, abaratar costes y cumplir el objetivo de reducir la aportación del sector público al PIB de 95 a $45 \%$ en cinco años. Además se ha flexibilizado la normativa que restringía las migraciones internas y salidas del país, se ha ampliado la autorización para crear cooperativas en varias actividades, aprobándose las primeras 224 y anunciándose que les seguirán otras 228 , y se ha facilitado el acceso a crédito nacional de los ciudadanos para comprar o reparar casas. También se informa de nuevas prospecciones petrolíferas y del levantamiento de un catastro, y la disposición más importante es la publicación en marzo de 2014 de medidas que eliminarán la dualidad monetaria, aunque esto es complejo y no se precisa bien cómo se hará. Sin embargo se ha señalado que no habría incrementos salariales generalizados hasta que crezca la producción y productividad, ${ }^{77}$ lo que denuncia que las reformas han aliviado poco los principales problemas económicos. Hoy

76 Mesa-Lago, 2012.

77 Ver Gramma, 2012, 1; Martínez, 2014; «Cuba», 2014. 
Cuba siegue importando alimentos por 2.000.000.000 \$, de lo que dependen dos tercios de su consumo, y si bien la oferta agraria se ha elevado un $8,7 \%$ el último año, el ahorro en la factura comercial sólo ha sido de $120.000 .000 \$ .^{78}$

En términos macroeconómicos la estimación del gobierno es que el PIB de Cuba creció en 2013 un 3,7 \%, porcentaje que la ONU reduce a 3,5, y la previsión para 2014 es un aumento menor: 2,2. En el mejor de los casos la cifra del pasado año iguala la media latinoamericana. El anterior el incremento fue del 3,1\%, peor de lo previsto, según se apuntó oficialmente, debido a que el sector de la construcción incumplió la planificación. En 2011 la elevación del producto fue del 2,7 \% y en 2009 y 2010 el Banco Mundial calcula que apenas alcanzó un 1,5. El trienio precedente la isla creció también por debajo del nivel medio de los países de América Latina, y si se cumplen los augurios de sus dirigentes, actualmente el escenario óptimo esperable es recobrar la paridad. El saldo reformista, pues, permitiría recuperar la senda de progreso de naciones vecinas, pero tras haber dejado un lastre negativo en el camino, al menos en los últimos 50 meses. $^{79}$

Para concluir, un magnífico libro reciente editado por Alonso y Vidal señala que el problema de las reformas cubanas recientes es que sus metas no están claras. Siguen un modelo de ensayo y error, pausado, más efectivo y menos dañino a corto plazo que los tratamientos de choque, pero que dificulta la simultaneidad de los cambios, cuando dicha efectividad depende en muchos casos de que se apliquen modificaciones en varios ámbitos a la vez, en interacción. Además el ritmo lento precisa liderazgo estable, lo que tropieza con el envejecimiento de la dirigencia revolucionaria y las dudas sobre la solvencia y posibilidad de sus sucesores de hacerse cargo de la situación, y con la necesidad de crear nuevas alianzar político-sociales en sectores beneficiarios de las reformas que mitiguen la conflictividad y permitan contrarrestar a los partidarios del inmovilismo. ${ }^{80}$

En el sentido expresado, las reformas pueden trastocar estructuras básicas del sistema político de Cuba, si no lo están haciendo ya, lo que obliga a la elite a cambios en sus acuerdos y en el modo de relacionarse con nuevos grupos sociales en ascenso y con la sociedad en general. Alonso señala que esto requiere acabar con el inmovilismo, rutinización e incerti-

78 Anuario, 2012.

79 Yzquierdo, 2013; Banco Mundial, 2012; «Cuba», 2012, 2013; ONU, 2013.

80 Alonso y Vidal (eds.), 2013. 
dumbre que caracterizan a dicho sistema político, con su estaticidad y burocratismo, para lo que propone un esfuerzo combinado de potenciación de la limitada participación popular en las decisiones, que aumentaría las adhesiones a las reformas, y de familiarización de la economía. ${ }^{81}$ En ese sentido Cuesta apunta que las actuales transformaciones no son resultado de un proceso natural de maduración del sistema socio-político y económico, sino de su agotamiento, lo que conlleva una dramática reestructuración que conmoverá sus cimientos y conduce a pensar que la transición será inevitable, pues sus causas desbordan los mecanismos de control del régimen revolucionario y responden a expectativas de bienestar insatisfechas y a nuevos universos de valores y relaciones en la población, por lo cual es la transición que será posible o cómo será posible la transición lo que requiere ser estudiado. ${ }^{82}$

Recibido el 08 de abril de 2013

Aceptado el 25 de abril de 2014

\section{Bibliografía}

Alienes, Julián: Características fundamentales de la economía cubana, La Habana, BNC, 1950.

Alonso, Aurelio: El laberinto tras la caída del muro, La Habana, Ciencias Sociales, 2006.

Alonso, José A. y Vidal, Pavel (eds.): ¿Quo vadis, Cuba?, Madrid, Catarata, 2013. Amnistía Internacional: El embargo estadounidense contra Cuba. Su impacto en los derechos económicos y sociales, Madrid, Editorial Amnistía Internacional (EDAI), 2009.

Anuario Estadístico de Cuba, La Habana, 2007-2012.

«¿Azúcar por armas?», BBC, 17/7/2013 (www.bbc.co.uk/mundo/noticias/ 2013/07/130717_cuba_corea_norte_barco_panama_intercambio_men.shtml).

Banco Central: Informe económico, La Habana, 2009.

Banco Internacional de Reconstrucción y Fomento (BIRF): Informe sobre Cuba, Washington, 1950.

Banco Mundial: «Perspectivas económicas», 2012 (www.bancomundial.org/ investigacion/).

Benítez Rojo, Antonio: La isla que se repite, Hanover, Norte, 1989.

81 Alonso, 2006.

82 Cuesta, 2014. 
«Brasil y México se lanzan a tomar posiciones en Cuba», El País, Madrid, 29/1/2014, 4.

Brundenius, Clae: «Revolutionary Cuba at 50», Latin American Perspectives, 36, 2009, 27-56.

Cancio, Wilfredo: «Turistas estadounidenses en Cuba», Las Américas, 18/10/2013 (www.diariolasamericas.com/america-latina/turistas-estadounidenses-quemas.html).

Carranza, Julio et al.: Cuba: la reestructuración económica, Madrid, CEAIEPALA/EEHA-CSIC, 1995.

«Castro dice que el plan de reformas no es perfecto», WVEN News, 3/3/2014 (www.wventv.com/2014/03/03/raul-castro-dice-que-el-plan-de-reformasno-es-perfecto-y-pide-un-analisis-critico/).

Castro, Abel: Quo vadis Cuba? Bloomington, Paralibro, 2012

Castro, Fidel: «Discurso. Clausura del XVI Congreso de la CTC», 1990 (www.cuba.cu/gobierno/discursos/1990/esp/f280190e.html).

Cave, Damian: «The Cuban evolution», New York Times, 1/3/2014, 27.

Censo de 1953, La Habana, Oficina del Censo, 1953.

«China y Cuba refuerzan relaciones», Telesur 30/5/2013 (www.telesurtv.net/-

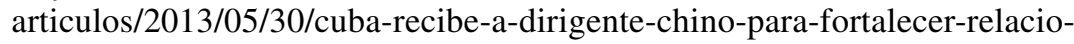
nes-428.html).

Comisión Económica para América Latina y el Caribe (CEPAL): El desarrollo económico de Cuba, Washington, 1958.

Comisión Económica para América Latina y el Caribe (CEPAL): La economía cubana, México, FCE, 2000.

«Congreso del PCC», Gramma, La Habana, 2014 (http://www.granma.cu/ granmad/secciones/6to-congreso-pcc/).

«Contradicciones del sistema», 2011 (www.laoveja100.wordpress.com/2011/04/ 25/las-contradicciones-del-sistema).

«Cuba acepta iniciar el diálogo con la UE», El País, Madrid, 6/4/2014, 4.

«Cuba crecerá 2,2 \%», El Financiero, Costa Rica, 21/12/2013 (www.elfinancie rocr.com/economia-y-politica/PIB-Cuba-crecera_0_431956807.html).

«Cuba establece normas para su proceso de unión monetaria», Nuevo Herald, Miami, 6/3/2014 (www.elnuevoherald.com/2014/03/06/v-print/1696016/ cuba-establece-normas-financieras.html).

«Cuba pronostica crecimiento económico de 3.7 \%», Notimex, 12/12/2012 (http://noticias.starmedia.com/economia/cuba-pronostica-crecimientoeconomico-3-7-en-2013.html).

«Cuba rebaja las previsiones de crecimiento», Habana Times, 4/12/2012 (www.havanatimes.org/sp/?p=76156).

«Cuba y Vietnam quieren aumentar su comercio», Nuevo Herald, Miami, 26/3/2014 (www.elnuevoherald.com/2014/03/26/1711527/cuba-y-vietnamquieren-aumentar.html). 
Cuban Research Institute: La diáspora cubana en el siglo XXI, Miami, Eriginal, 2011.

Cuesta, Manuel: Cuba: democracia para una nación posible, Madrid, Instituto Elcano, 2014 (www.realinstitutoelcano.org/wps/portal/web/rielcano_es/ contenido?wcm_global_context=/elcano/elcano_es/zonas_es/america+ latina/dt30-2008\#.Uxb1O87Xwro).

Delegación de la Unión Europea en Cuba: www.eeas.europa.eu/delegations/cuba/ index_es.htm (2014).

Díaz-Briquets, Sergio y Pérez-López, Jorge: Corruption in Cuba, Austin, Texas University, 2006.

Domínguez, Jorge et al.: Debating US-Cuban relations, New York, Routledge, 2011.

«Elite del exilio cubano busca cambio en la política», 2014 (www.cubastudy group.org/index.cfm/inicio).

Espacio Laical, La Habana, Centro Cultural Padre Félix Varela, 2005.

Espinosa, Óscar: Cambios en Cuba: pocos, limitados y tardíos, La Habana, 2011 (www.reconciliacioncubana.files.wordpress.com/2011/03/cambios-encuba.pdf).

«Fidel Castro tras anuncio de Obama», El Comercio, 13/4/2009 (http://elcomer cio.pe/mundo/europa/fidel-castro-anuncio-obama-cuba-resistira-no-pedirali mosnas-noticia-272821).

Fondo Monetario Internacional (FMI): www.imf.org/external/spanish/index.htm (2012).

Fuente, Alejandro: «Race, cultura, politics», en Pérez-Stable (ed.), 2007, 138-62.

Goldberg, Jeffrey: «Cuban model doesn't even work for us anymore», The Atlantics, 8/9/2010 (www.theatlantic.com).

González, Edward: Cuba exiles on trade embargo, New York, McFarland, 2007.

Gramma, La Habana, 8/12/2012, 1.

Hatton, Timothy et al. (eds.): The new comparative Economic History, London, MIT, 2007.

Ibarra, Jorge: Cuba: 1989-1959, La Habana, Ciencias Sociales, 1995.

Iñiguez, Luisa: «Espacio territorio y desigualdades sociales en Cuba», en PérezVillanueva (comp.), 2006, 116-37.

Junta Central de Planificación (JUCEPLAN): Economía Cubana 1960-75, La Habana, 1977.

Latin Focus: www.latin-focus.com (2014).

Luzón, José L.: Economía, población y territorio en Cuba, Madrid, Cultura Hispánica, 1989.

Maddison, Angus: Dos crisis: América Latina y Asia, México, FCE, 1988.

Malamud, Carlos: «CELAC en La Habana», Infolatam, 2/2/2014 (http://www.infolatam.com/2014/02/02/celac-en-la-habana-la-cumbre-delas-oportunidades-perdidas/). 
Marqués, María Antonia: Estado y economía en la antesala de la revolución, La Habana, Ciencias Sociales, 1994.

Martínez, Fernando: Socialismo, liberación y democracia, La Habana, Ocean Sur, 2006.

Martínez, Leticia: «Gaceta oficial publica medidas rumbo a unificación monetaria», Cuba Debate 6/3/2014 (www.cubadebate.cu/categoria/temas/economia-temas/)

Mesa-Lago, Carmelo: La economía de Cuba socialista, Madrid, Playor, 1985.

Mesa-Lago, Carmelo: Breve historia económica de la Cuba socialista, Madrid, Alianza, 1996.

Mesa-Lago, Carmelo: Economía y bienestar social en Cuba a comienzos del siglo XXI, Madrid, Colibrí, 2003.

Mesa-Lago, Carmelo: «Política y desempeño económicos comparados en modelos de mercado, socialista y mixto», en Santamaría (coord.), 2006, 119-52.

Mesa-Lago, Carmelo: «Balance económico-social de 50 años de revolución», América Latina Hoy, 52, 2009, 41-61.

Mesa-Lago, Carmelo: «El Congreso del PCC y la economía», El País, Madrid, 16/5/2011, 23.

Mesa-Lago, Carmelo: Cuba en la era de Raúl Castro, Madrid, Colibrí, 2012.

Morales, Esteban: «Cuba: corrupción ¿la verdadera contrarrevolución?», Kaos, 24/6/2010 (http://old.kaosenlared.net/noticia_imprimir.php?id_noticia= 123941).

MOxLAD: www.moxlad.fcs.edu.uy (2014).

Navatón, Antonio: «Venezuela, precio del rescate cubano», El País, Madrid, 17/3/2014, 27.

Nelson, Lowry: Rural Cuba, Minneapolis, Minnesota University, 1950.

Nova, Armando: La agricultura en Cuba, La Habana, Ciencias Sociales, 2009.

Oficina Nacional de Estadística (ONE): Cuba: indicadores seleccionados, La Habana, 2002.

Oficina Nacional de Estadística (ONE): Series de cuentas nacionales de Cuba, La Habana, 2007.

Oficina Nacional de Estadística (ONE): Panorama económico y social de Cuba, La Habana, 2008.

Oppenheimer, Andrés: La hora final de Castro, Barcelona, Vergara, 1992.

Oppenheimer, Andrés: «Raúl Castro compara tiempo», El País 25/4/2011, 21.

Organización de las Naciones Unidas (ONU): Situación y perspectivas de la situación económica mundial, New York, 2013.

Pérez-López, Jorge: The economics of Cuban sugar, Pittsburgh, Pittsburgh University, 1994.

Pérez-López, Jorge: Cuba's second economy, New York, Transaction, 1995.

Pérez-Stable, Marifeli: El exilio de Miami afronta los cambios en Cuba, Madrid, Instituto Elcano, 2008 (www.realinstitutoelcano.org/wps/portal/rielcano/ 
contenido?wcm_glogal_Context=/elcano/elcano_es/zonas_es/america+ latina/ari+95-2003).

Pérez-Stable, Marifeli: The United States and Cuba, New York, Routledge, 2010.

Pérez-Stable, Marifeli: «Raúl no es Fidel», El País, Madrid, 21/3/2014, 4.

Pérez-Stable, Marifeli (ed.): Looking forward: comparative perspectives on Cuba s trasition, Notre Dame, Notre Dame University, 2007.

Pérez-Villanueva, Omar (ed.): Reflexiones sobre economía cubana, La Habana, Ciencias Sociales, 2004.

Pérez-Villanueva, Omar: La estrategia económica cubana, La Habana, Universidad de La Habana, 2008.

Pollit, Brian: «Estudios acerca del nivel de vida rural en la Cuba pre-revolucionaria», Teoría y Práctica, 42, 1967, 187-219.

Prados, Leandro: «Inequality and poverty in Latina America», en Hatton et al. (eds.), 2007, 276-99.

Programa de las Naciones Unidas para el Desarrollo (PNUD): Human development report, New York, 1995.

Proyecto Varela, México, ODCA, 2004.

Rodríguez, Carlos R.: Cuba en el tránsito al socialismo, México, Siglo XXI, 1978.

Rodríguez, José L.: Estrategia del desarrollo económico de Cuba, La Habana, Ciencias Sociales, 1999.

«Rusia condona a Cuba 29.000 millones en deuda», Rianovosti, 10/12/2013 (www.sp.ria.ru/international/20131210/158747551.html).

Sánchez, Yaoani: http://lageneraciony.com/, 2014.

Sánchez, Jorge y Triana, Juan: An overview of the Cuban economy, Madrid, Instituto Elcano, 2008.

Santamaría, Antonio: «Azúcar y revolución. El sector de la economía cubana durante los primeros doce años de la Revolución (1959-1970)», Revista de Historia Económica, 12/1, 1994, 111-41.

Santamaría, Antonio: «El crecimiento económico de Cuba republicana (19021959). Una revisión y nuevas estimaciones en perspectiva comparada», Revista de Indias 218, 2000, 505-45.

Santamaría, Antonio: Sin azúcar no hay país. La industria azucarera y la economía cubana (1919-1939), Sevilla, Universidad de Sevilla, Escuela de Estudios Hispano-Americanos-CSIC, Diputación, 2002.

Santamaría, Antonio: «Açucar nas Americas», A rapadura o fusca. Cana, cultura, sociedade, Salvador de Bahia, Goethe-Institut, 2009, 108-32.

Santamaría, Antonio: «Raúl Castro acelera los cambios para atenuar la crisis». Radio Francia Internacional, 2010 (www.espanol.rfi.fr/americas/20101109raul-castro-acelera-los-cambios-para-atenuar-la-crisis).

Santamaría, Antonio: «Dos siglos de especialización y dos décadas de incertidumbre. La historia económica de Cuba, 1800-2010», en Bertola, Luis y Pablo Gerchunoff (comps.), Institucionalidad y desarrollo en América Latina, San- 
tiago, CEPAL, 2011, 135-190 (www.eclac.cl/publicaciones/xml/0/44960/ Institucionalidad_y_desarrollo_final.pdf).

Santamaría, Antonio (coord.): América Latina. Crecimiento económico sostenido y equidad, monográfico de Debate y Perspectivas. Cuadernos de Historia y Ciencias Sociales, 5, Instituto de Cultura, Fundación Mapfre, Madrid, 2006. Santamaría, Antonio y Lillo, Margarita: «La Unión Europea y Colombia. Historia y desafío», Anuario de Estudios Americanos, 66-1, Sevilla, 2009, 289-313.

«Sector informal», 2012 (www.cubasindical.blogspot.com.es/2012/02/sectorinformal.html).

«Segunda declaración de La Habana», 1962 (www.ciudadseva.com/textos/otros/ 2declara.htm).

Tamayo, Juan: «Muerte de Chávez representa un duro golpe para Cuba», Nuevo Herald, Miami, 6/3/2013 (http://www.elnuevoherald.com/2013/03/05/ 1423022/muerte-de-chavez-representa-duro.html).

Temas: «¿Qué es Temas?», Temas, La Habana,1, 1995, 3.

Thomas, Hugh et al.: La revolución cubana 25 años después, Madrid, Playor, 1985.

Thorp, Rosemary: Progress, poverty and exclusion. An economic history of Latin America in the 20 $0^{\text {th }}$ century, New York, IBD, 1998.

Thorp, Rosemary (ed.): América Latina en los años treinta, México, FCE, 1999.

Toro, Carlos: «Algunos aspectos económicos del movimiento obrero cubano», $\mathrm{La}$ República Neocolonial, La Habana, Ciencias Sociales, 1975, 217-76.

«Trabajo por cuenta propia», Cuba Debate, La Habana, 19/3/2014 (www.cubade bate.cu/categoria/temas/economia-temas/).

Vicent, Mauricio: «Ofensiva contra la disidencia en el aniversario de la crisis de las avionetas», El País, Madrid, 24/2/1997, 3.

Vicent, Mauricio: «Cuba y China consolidan su alianza», El País 8/6/2011, 4.

Vidal, Pavel: Proyecciones macroeconómicas de una Cuba sin Venezuela, 2014 (www.cubastudygroup.org/index.cfm/inicio).

Yoss: «Los pilotos dicen», Temas, 65, La Habana, 2011, 69-71.

Yzquierdo, Abel: «El PIB no alcanza el incremento planificado», Gramma, La Habana, 2/12/2013, 1.

Zuaznávar, Ignacio: La economía cubana en la década del 50, La Habana, Ciencias Sociales, 1988. 